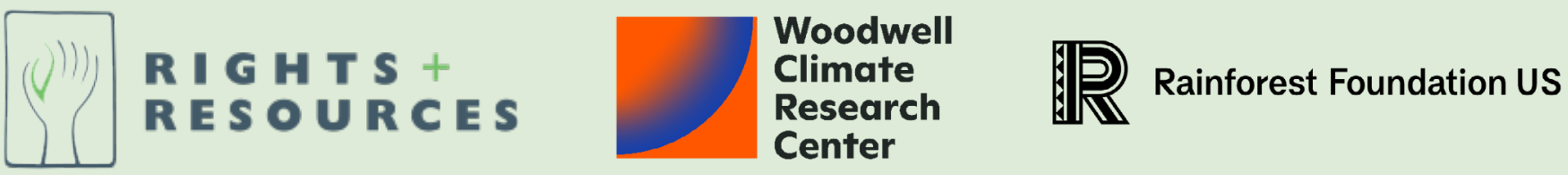

\title{
Significance of Community-Held Territories in 24 Countries to Global Climate
}

D ecades of inaction and watered-down commitments have pushed the planet to the brink of potentially irreversible changes, with untold consequences for life as we know it. Failure to meet the goals of previous international conventions and agreements could presage a similar fate for the Paris Agreement and the Sustainable Development Goals if leaders and decision makers do not heed the message of Indigenous Peoples, Afro-Descendant Peoples and local communities - and particularly the women within these groups: that no plan to save the planet can succeed if it excludes the very people who, for generations, have stewarded the world's lands and waters, helping to maintain the biodiversity and ecosystem services upon which all life depends.

Over the course of a series of high-level summits to develop the post-2020 agenda, the Global Alliance of Territorial Communities (GATC) has emerged as a leading voice, representing the concerns and demands of traditional communities across 24 countries containing $60 \%$ of the world's tropical forest area. ${ }^{1}$ In response to the GATC's leadership, the Rights and Resources Initiative (RRI), Woodwell Climate Research Center, and Rainforest Foundation US (RFUS) have jointly consolidated and produced new research based on the latest available geospatial data, official figures, and independently validated area estimates in order to better understand the scale and significance of GATC members' contributions to the climate and biodiversity agenda.

This research provides a timely reminder of the global significance of community-held lands and territories; their importance for the protection, restoration, and sustainable use of tropical forestlands across the world; and the critical gaps in the international development architecture that have so far undermined progress towards the legal recognition of such lands and territories.

Our findings indicate that Indigenous Peoples, Afro-Descendant Peoples, and local communities customarily hold and use at least 958 million hectares (mha) of land in the 24 reviewed countries but have legally recognized rights to less than half of this area (447 mha). Their lands are estimated to store at least 253.5 Gigatons of Carbon (GtC), playing a vital role in the maintenance of globally significant greenhouse gas sinks and reservoirs. However, the majority of this carbon (52 percent, or $130.6 \mathrm{GtC}$ ) is stored in community-held lands and territories that have yet to be legally recognized.

This absence of tenure security renders communities and their lands and forests vulnerable to encroachment and external pressures, hampering their ability to sustainably govern these areas, pursue their self-determined priorities, and meet their livelihood needs.

1 RIGHTS + RESOURCES INITIATIVE 


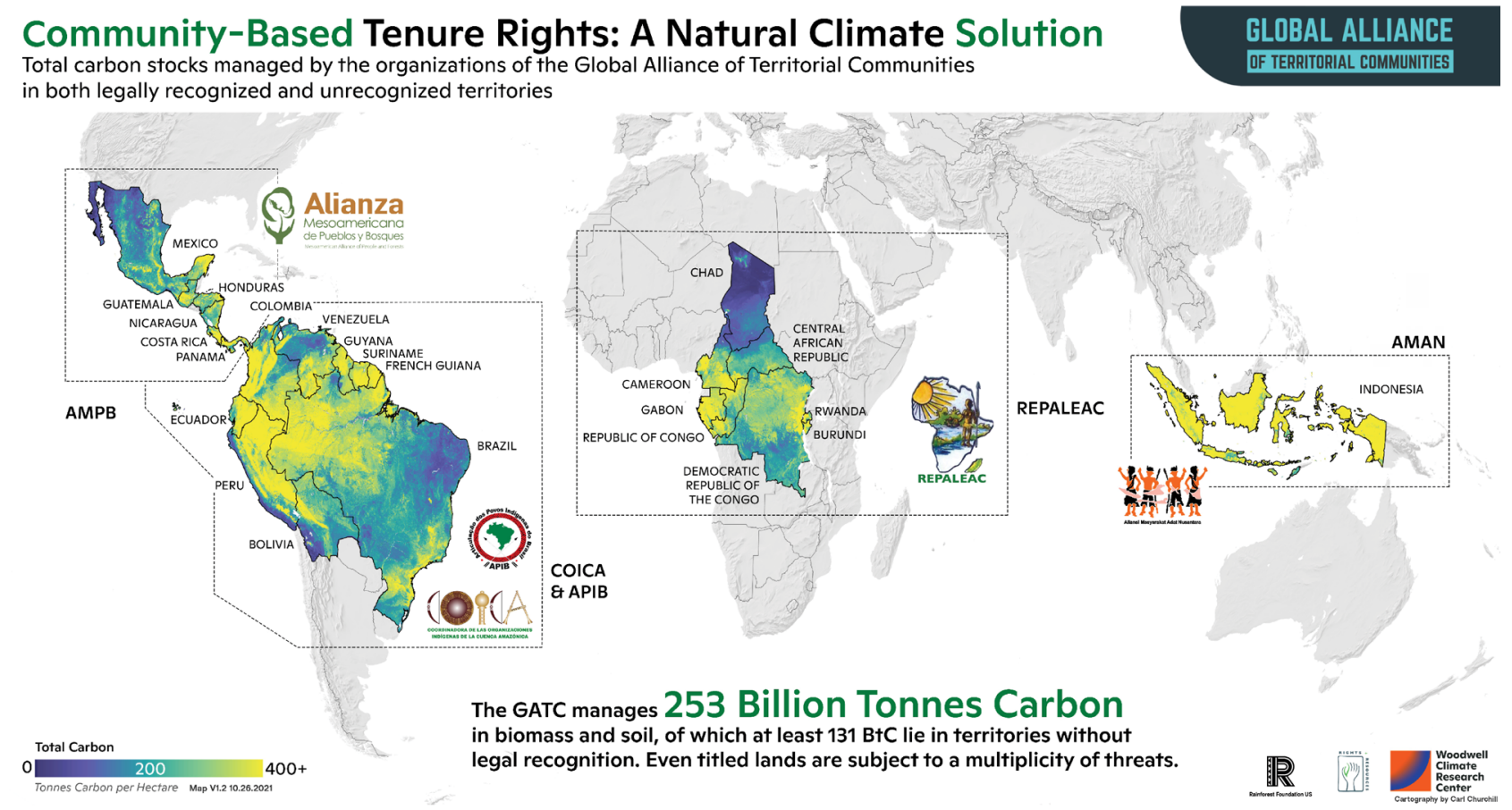

\section{Urgent Need for Transformative Action}

There is now growing consensus that secure collective land rights are fundamental to the realization of just, effective, and sustainable climate and biodiversity actions and the transformative changes that are urgently needed. ${ }^{2}$ Despite such recognition, climate financing institutions have yet to dedicate the resources required to secure communities' land tenure rights. In fact, less than $1 \%$ of official development assistance for climate change mitigation and adaptation has been earmarked for community forestry over the last decade, and only a tiny fraction of this amount was dedicated to projects advancing collective land and forest tenure rights. ${ }^{3}$

Moreover, analysis of nationally determined contributions (NDCs) to the Paris Agreement finds that the governments of only eight of the 24 GATC member countries have committed to strengthening community land rights as a part of their climate change strategies. ${ }^{4}$ Whether these non-binding commitments translate into action remains to be seen, but in the absence of dedicated international financing support and effective recognition of community-held lands and territories, the risk of furthering forest and biodiversity loss, land-related conflicts, and the weakening of the 2030 sustainable development agenda remains high.

Yet, an RRI review of opportunities to accelerate tenure reforms in countries with GATC presence shows that such changes are both possible and actionable. Of the 24 jurisdictions analyzed, 22 have at least one legal framework for recognizing communities' tenure rights, and, of those, at least 10 have legislation for recognizing their full ownership rights. ${ }^{5}$ For example, by implementing existing legislation in just two countries - Indonesia and Democratic Republic of the Congo - over 200 mha of Indigenous and local community lands could be recognized, helping to protect an area larger than the combined area of the European Union's five largest member states: France, Spain, Sweden, Germany, and Poland. 
Of the 20 countries where RRI completed assessments of the political-economic context and institutional capacities, at least 14 countries have satisfactory or partially satisfactory enabling conditions to implement tenure reform overall, though government willingness to support such processes was found to be inadequate or only partially inadequate in 15 of the 20 countries. $^{6}$ But as history reveals, policy positions and perspectives are dynamic and everchanging.

\section{Failure to recognize collective land rights potentially risks the equivalent of up to 15 times the world's 2020 energy-related Co2 emissions.}
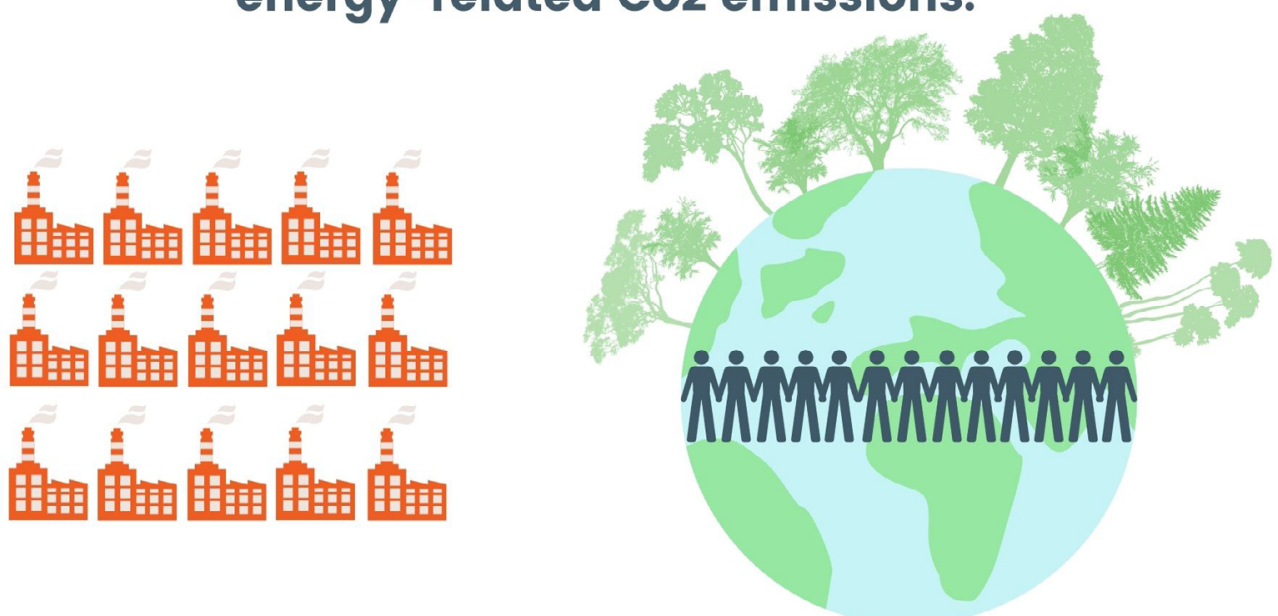

\section{Respect for and enforcement of communities' rights remain critical for supporting their continued stewardship of landscapes and biodiversity therein.}

Within the contexts of the global climate and biodiversity talks, the growing demand for rightsbased actions presents unparalleled opportunities to both galvanize political support for this critical agenda and mobilize the financial and technical resources needed to help countries deliver on this crucial step toward a more just and sustainable future. Achieving such ends may require the international community to redefine what counts as a climate contribution when all ecosystem services are required for a stable planet, and how to make the legal recognition and protection of community-held lands and territories a central tenet of all national and international actions, commitments and investments.

Evidence shows that the land stewardship and sustainable development contributions of Indigenous Peoples, Afro-Descendant Peoples, and local communities are so globally significant that the world can simply not afford to exclude them from critical decision-making processes. Securing and protecting their rights and livelihoods are necessary steps for averting systemic risks that could further accelerate the unfolding global environmental crises. More must be done to strengthen and expand communities' tenure rights, leverage all performance and market-based financing mechanisms, frameworks, and approaches to achieve such ends, and ensure rightsholders are involved in all future land use and land conservation decisions.

The stability of the climate and the future of humanity now depend on the creation of policy mechanisms that value not only the sequestration capacity of community-held lands and forests, but also the standing stocks of carbon, together with the broad range of globally significant ecosystem services that communities across the tropics manage and maintain. 


\section{CALL TO ACTION}

As negotiators and decision makers grapple with how to secure a safer, healthier planet for current and future generations, the rights of Indigenous Peoples, Afro-Descendant Peoples, and local communities can no longer be an afterthought. They must be recognized as central to the realization of global climate and biodiversity goals. In order to empower them to play their vital role in protecting lands and forests, the following five principles should be understood as nonnegotiable for a just transition:

1. Recognition and enforcement of the land, territorial, and resource rights of Indigenous Peoples, Afro-descendant Peoples, and local communities - and the women within these groups.

2. Respect for the right to free, prior, and informed consent (FPIC) where projects may impact community territories.

3. Increase dedicated climate, conservation, and development funding and direct access for communities and the initiatives they lead to secure, protect and steward their lands, and ensure their full and effective participation in all nature-based climate and conservation actions and decisions, from design through implementation.

4. An immediate end to criminalization, intimidation, and killing of Indigenous, Afro-descendant, and community land and environmental rights defenders.

5. Incorporation of traditional knowledge into climate change policies and practices.

For more information on these findings, please contact Chloe Ginsburg at cginsburg@rightsandresources.org.

${ }^{1}$ The 24 jurisdictions where GATC has members are: Bolivia, Brazil, Burundi, Cameroon, Central African Republic, Chad, Colombia, Democratic Republic of the Congo, Costa Rica, Ecuador, French Guiana (France), Gabon, Guatemala, Guyana, Honduras, Indonesia, Mexico, Nicaragua, Panama, Peru, Republic of Congo, Rwanda, Suriname, and Venezuela. Within this brief, area-based information concerning French Guiana is specific to the administrative department, whereas legal analysis considers the national laws and international commitments made by France as appropriate. Tropical forest area is calculated using data from FAO. 2020. Global Forest Resources Assessment 2020: Main report. Rome. Available at: https://www.fao.org/documents/card/en/c/ca9825en/. See also GATC website: https://globalalliance.me/.

2 See Intergovernmental Panel on Climate Change. 2019. Special Report on Climate Change and Land. Available at: https://www.ipcc.ch/srccl/; FAO and FILAC. 2021. Forest Governance by Indigenous and Tribal People. An Opportunity for Climate Action in Latin America and the Caribbean. Santiago. Blackman, A. 2015. Strict versus Mixed-use Protected Areas: Guatemala's Maya Biosphere Reserve. Ecological Economics 112: 14-24; Nepstad, D. et al. 2006. Inhibition of Amazon Deforestation and Fire by Parks and Indigenous Lands. Conservation Biology 20(1): 65-73; Nolte, C. et al. 2013. Governance Regime and Location Influence Avoided Deforestation: Success of Protected Areas in the Brazilian Amazon. PNAS 110(13): 4956-4961; Stevens, C. et al. 2014. Securing Rights, Combating Climate Change: How strengthening community forest rights mitigates climate change. WRI and RRI, Washington, DC; Wren-Lewis, L., Becerra-Valbuena, L., \& Houngbedji, K. 2020. Formalizing land rights can reduce forest loss: Experimental evidence from Benin. Science Advances, 6(26).

${ }^{3}$ Rainforest Foundation Norway (RFN). 2021. FALLING SHORT Donor funding for Indigenous Peoples and local communities to secure tenure rights and manage forests in tropical countries (2011-2020). Available at: https://www. regnskog.no/en/news/falling-short.

${ }^{4}$ These countries are Bolivia, Cameroon, Chad, Colombia, Costa Rica, Guatemala, Indonesia, and Nicaragua.

${ }_{5}^{5}$ The two countries lacking any legal framework for recognizing community-based tenure rights are: Burundi and Rwanda.

${ }^{6}$ For more on the updated methodology employed for this assessment see: Rights and Resources Initiative. 2021. Supplement: Opportunity Framework 2021. Rights and Resources Initiative, Washington, DC. Available at: https:// rightsandresources.org/publication/global-significance-of-community-held-territories-in-24-countries-to-climate-goals. See also: Rights and Resources Initiative. 2020. The Opportunity Framework 2020. Rights and Resources Initiative, Washington, DC. Available at: https://rightsandresources.org/wp-content/uploads/2020/09/Opp-Framework-Final.pdf. 


\section{About the Rights and Resources Initiative}

The Rights and Resources Initiative is a global Coalition of 21 Partners and more than 150 rightsholders organizations and their allies dedicated to advancing the forestland and resource rights of Indigenous Peoples, Afro-descendant Peoples, local communities, and the women within these communities. Members capitalize on each other's strengths, expertise, and geographic reach to achieve solutions more effectively and efficiently. RRI leverages the power of its global Coalition to amplify the voices of local peoples and proactively engage governments, multilateral institutions, and private sector actors to adopt institutional and market reforms that support the realization of their rights and self-determined development. By advancing a strategic understanding of the global threats and opportunities resulting from insecure land and resource rights, RRI develops and promotes rights-based approaches to business and development and catalyzes effective solutions to scale rural tenure reform and enhance sustainable resource governance.

RRI is coordinated by the Rights and Resources Group, a non-profit organization based in Washington, DC. For more information, please visit www.rightsandresources.org.

\section{PARTNERS}
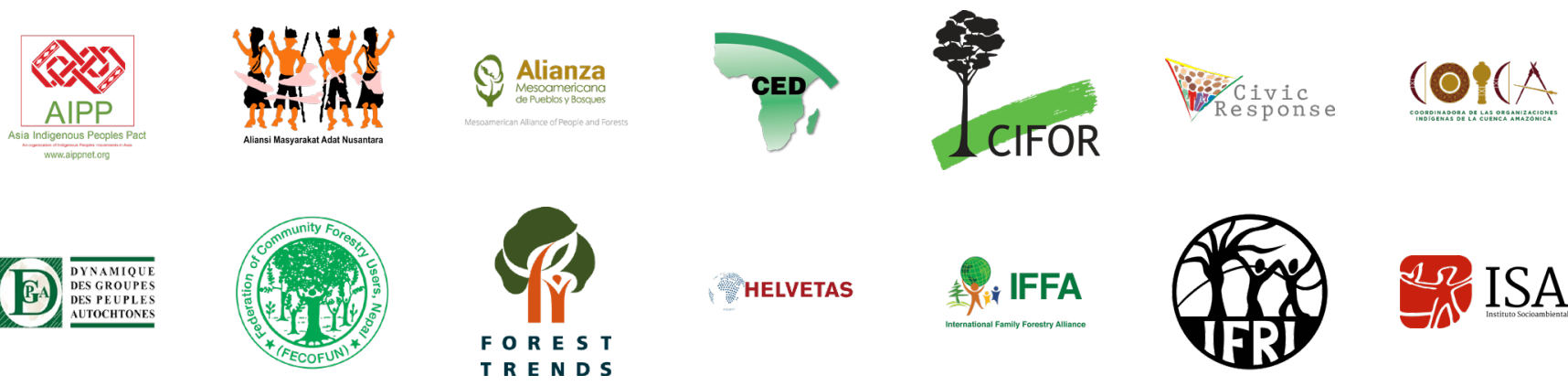

MHELVETAS
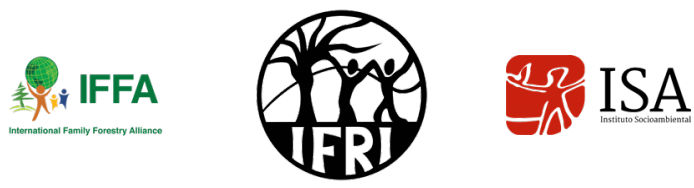

路 Landesa
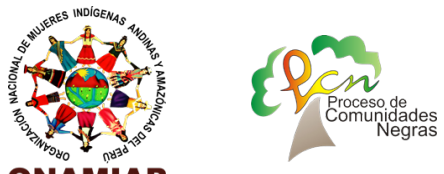

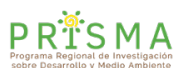

है RECOFTC
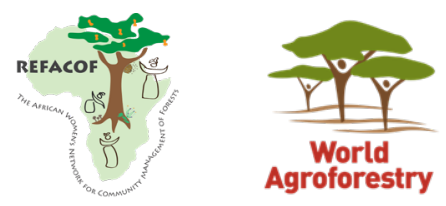

\section{SPONSORS}
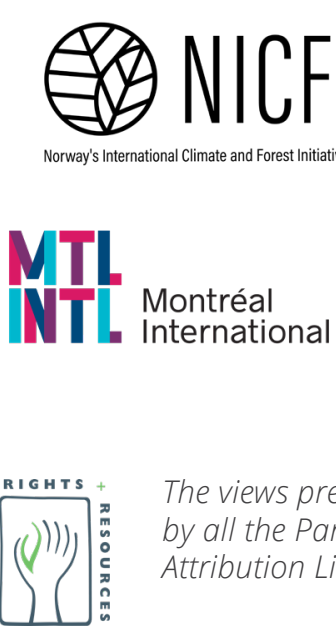

Montréal Internationa

\section{FORDFOUNDATION}

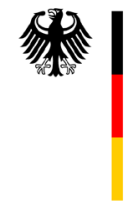

Federal Ministry for Economic Cooperation and Development

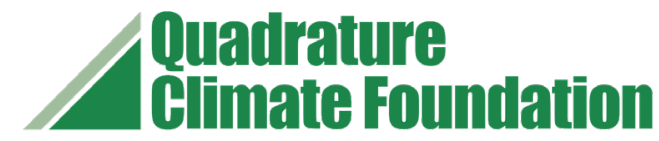

The views presented here are not necessarily shared by the agencies that have generously supported this work, nor by all the Partners and Affiliated Networks of the RRI Coalition. This work is licensed under a Creative Commons Attribution License CC BY 4.0 . 